\title{
Aesthetic and Perception: Indicators of perceiving the rural landscape
}

\author{
Muhamad Solehin Fitry Rosley ${ }^{1}$, Hasanuddin Lamit², Syumi Rafida ${ }^{1}$ \\ 1Phd candidate, ${ }^{2}$ Associate Prof, \\ Department of Landscape Architecture, Faculty of Built Environment, \\ Universiti Teknologi Malaysia \\ solzfitry@gmail.com
}

\begin{abstract}
The assessment of authentic beauty of rural landscape requires valid indicators of visual aesthetic and preference of experts and stakeholders with the application of theory driven indicator. The theory driven indicators are tested through a systematic approach by using Research Model Analysis. The design, stratification and administration of questionnaire with special reference to demographic factors were based on the 5 photographs taken in to attain this, the paper aimed at produces valid indicators that considered perception selected rural area for 126 stakeholders using Different Item Functioning analysis. The findings identify Complexity as the valid indicator that agreed by stakeholders.
\end{abstract}

Keywords: theory driven indicators, stakeholder's perception, validation, reliability

eISSN 2398-4295 @ 2017 The Authors. Published for AMER ABRA by e-International Publishing House, Ltd., UK. This is an open access article under the CC BY-NC-ND license (http://creativecommons.org/licenses/by-ncnd/4.0/). Peer-review under responsibility of AMER (Association of Malaysian Environment-Behaviour Researchers), ABRA (Association of Behavioural Researchers on Asians) and cE-Bs (Centre for EnvironmentBehaviour Studies), Faculty of Architecture, Planning \& Surveying, UniversitiTeknologi MARA, Malaysia.

http://dx.doi.org/10.21834/ajbes.v2i6.31 


\section{Introduction}

Rural landscape plays important roles in providing the needs of the people. For instance researchers such as Sayadi et al. (2009) and Bratli et al. (2006) identified the roles of rural landscape as retreat place for city dwellers and as food providers for the people. In addition, most of the rural landscape holds special place in preserving the unique characters of the people. This is reflected by the overall landscape composition of the place. The idyllic settings and limited access to modernization somehow contributed to the preservation of aesthetic aspect in rural landscape. As according to the European Landscape Convention (2002), landscape is the process of how people perceived and interacted to the surrounding. In other words, the landscape is resulted by human activities which include the people's perception. As part of preserving these characters, a visual assessment based on people perception is a must. One of the scopes is assessing the aesthetic values that embedded in the landscape. However, addressed by Zube' et al. (1982) the process of perception rather to focus on objective attributes than the subjective aspects that inherited in the existing landscape. This resulted, the current assessment neglecting the actual meaning of landscape. A landscape perception should be based on emotional and psychological attachment of the people towards their surrounding (Lothian 1999). Thus, the indicators of the assessment should able to measure the emotional attachment. The concern of validation and how far the existing indicators are reliable has been discussed by many researchers. Fry et al. (2009) posits that the existing indicators are adopted from various landscape themes and failed to measure people perception in a specific setting.

In addition, indicators to assess the rural landscape should homogenously represent people perception regardless their background values. As highlighted by Negev (2012), factors such as cultural values, beliefs, demographics contribute to the differences in people perception and most of all in deciding the valid indicators. Therefore this paper aimed to investigate on people perception focusing on stakeholder's perception in order to seek the similarities of them in perceiving the rural landscape.

\section{Literature Review}

The indicators should able to capture the actual condition of landscape which is closely related to human psychology. Thus, the indicators need to be precise and able to measure people perception. Researcher such as Tveit et al. (2006) and Ode et al. (2009) preferred in predicting human perception based on theory driven approach. This is to ensure that the existing indicators are derived from underpinning concept, related to aesthetic human perception and strongly attached to human psychological aspect.

These selected indicators were a compilation of several theories that discussed on human perception and preference. However, Fry et al. (2009) firmly stated that some of the theory based driven indicators have less impact on human preference and perception especially in a specific landscape theme such as the rural landscape. Certain indicators 
could be perceived differently in other landscape themes. Therefore in this case, these indicators need to be tested in term of reliability and validity in assessing the rural landscape setting.

Theories

Indicator

\author{
Prospect and refuge Theory \\ Biophilia Theory \\ Aesthetic of care \\ Restorative landscape Theory \\ Historic landscape Theory \\ Topophilia Theory \\ Information Processing Theory \\ Spirit of Place \\ Habitat Theory
}

\begin{tabular}{|c|c|c|}
\hline Mystery & Legibility & \\
\hline Disturbance & Complexity & \\
\hline \multicolumn{3}{|l|}{ Stewardship } \\
\hline Naturalness & Ephemera & \\
\hline \multicolumn{3}{|l|}{ Historicity } \\
\hline \multicolumn{3}{|l|}{ Coherence } \\
\hline & Coherence & Legibility \\
\hline \multicolumn{3}{|l|}{ Imageability } \\
\hline Legibility & Mystery & \\
\hline
\end{tabular}

Figure 1:

\section{Methodology}

The methodology is divided into three different stages. The first part is through metadata analysis. It is a process of sorting and comparative technique of existing guidelines based on a vast literature review in order to identify the reliable indicators from theoretical aspect. The quantity of existing indicators was narrowed down to seven indicators namely Mystery, Legibility, Coherence, Stewardship, Naturalness, Legibility, Openness, and Complexity (Figure 2)

\begin{tabular}{|c|c|}
\hline Indicators & Definition \\
\hline Mystery & $\begin{array}{l}\text { Mystery is developed by a high degree of inquiry and curiosity of people's mind for an exploration in wild } \\
\text { and uncommon landscape. It led to uncertainty experience which either resulting safe or danger (Stamps } \\
\text { 2004). }\end{array}$ \\
\hline Legibility & $\begin{array}{l}\text { Reflect the visual accessibility of ease movement, provide a safe feeling of way finding by using a } \\
\text { dominant character in the landscape such as landmark outstanding landscape character(Stamps 2004) }\end{array}$ \\
\hline Coherence & $\begin{array}{l}\text { Coherence portrays a harmony arrangement of landscape composition such as a unity in color and } \\
\text { texture of the landscape(Stamps 2004). }\end{array}$ \\
\hline Stewardship & $\begin{array}{l}\text { Stewardship relates to the well management and care of surrounding; neatness and ideal condition of the } \\
\text { landscape (Ode et al. 2010; Ode \& Fry 2002) }\end{array}$ \\
\hline Openness & $\begin{array}{l}\text { Openness refers to the degree of visibility and spaces within the surroundings (Tveit et al. 2006). } \\
\text { Openness gives a sense of accessibility and movement. }\end{array}$ \\
\hline Naturalness & $\begin{array}{l}\text { Naturalness reflects the degree of wilderness, untouchable or facing a minimum impact of human } \\
\text { activities. }\end{array}$ \\
\hline Complexity & $\begin{array}{l}\text { Complexity encompasses the diversity and richness of landscape features. The complexity refers to } \\
\text { content and possibilities of an exploration. }\end{array}$ \\
\hline Disturbance & Disturbance indicates the low degree of coherence, management and composition(Tveit et al. 2006) \\
\hline
\end{tabular}
Adapted from Rosley et al.( 2013)

Figure 2: 
This is followed by a second stage of pilot study. A group of respondents consist of 80 students of first year and final year students of architecture, landscape architecture and urban and regional planning disciplines. A total of 5 images of out of 25 images need to evaluate by these respondents (Figure 3 ). These images were selected by the expert panels in order to reduce the bias. The images should consists of three different layers foreground, middleground and background (Arriaza et al. 2004)

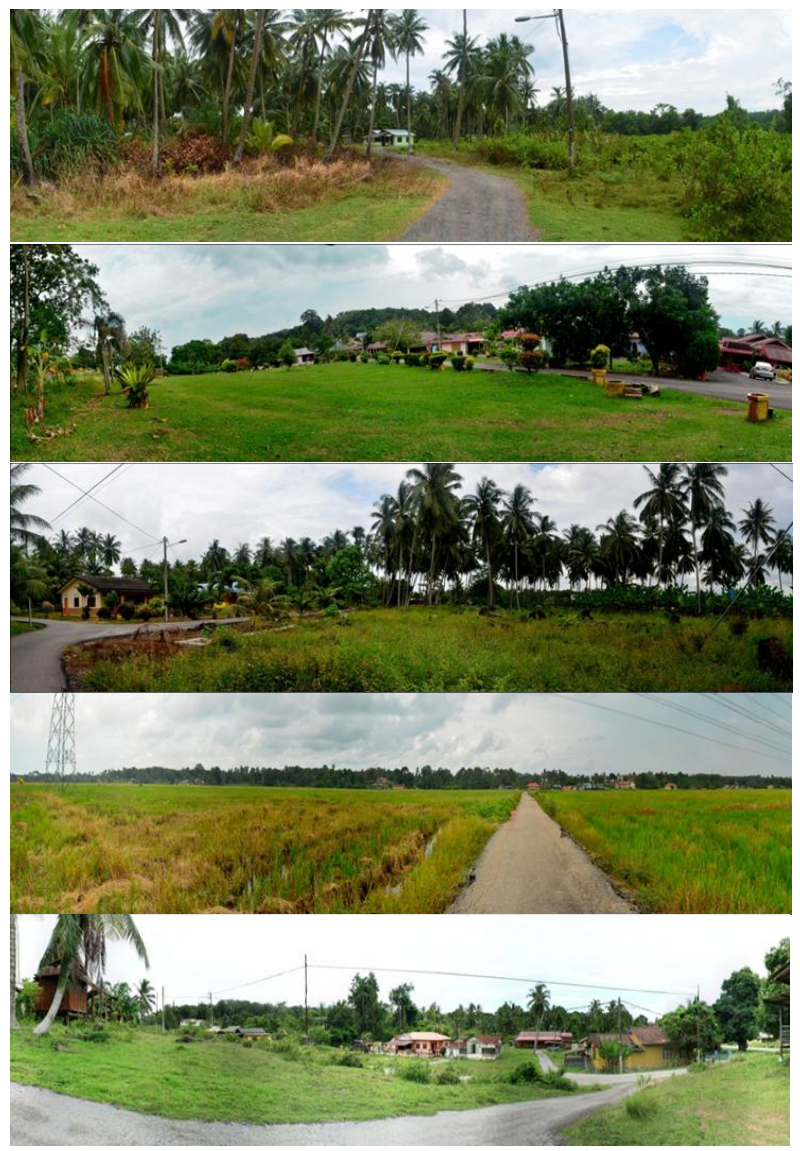

Figure 3:

The respondents then were required to assess the images based on Likert rating. Palmer \& Hoffman( 2001) highlighted that the technique manages to help the respondents 
assessing the images effectively. The Likert rating in the study started from 1 represents the lowest degree, to 5 , represent the highest degree of preference. This is followed by a separate analysis- to identify the validity of the indicators, based on several criteria.

\subsection{Reliability Test}

Despite the rating technique is being favoured, it is difficult to establish an equal interval in rating system to present the preference value of respondents (Sapawi \& Said 2012).Thus, lead a bias result in deciding the validity and reliability of the indicators. In this case, this study implemented Rasch Model in converting the rating system into a logistic model based on item response theory (IRT). The conversion helps to identify the reliability and validity of the rating based on the items -photographs and respondents

Table 1.

\begin{tabular}{ccc} 
No & Person Reliability & Person Separation \\
\hline 1 & 0.76 & 1.96 \\
2 & 0.79 & 1.97 \\
3 & 0.81 & 2.07 \\
4 & 0.79 & 1.92 \\
5 & 0.80 & 1.99 \\
\hline & & \\
No & Item Reliability & Item Separation \\
\hline 1 & 0.93 & 3.62 \\
3 & 0.93 & 3.77 \\
4 & 0.96 & 4.72 \\
5 & 0.94 & 4.02 \\
& 0.97 & 6.06 \\
\hline
\end{tabular}

In statistic study, reliability is a process of consistency of work and response (Palmer \& Hoffman 2001). The relevant coefficient of reliability is between $0.7-0.8$ in any statistic study. As shown in table 3 and 4 above, all the values of person reliability and item reliability indicate value between 0.76 to 0.97 , sufficient to show the consistency of the respondents and the evaluated images. However in Rasch analysis, person separation and item separation values should be considered as part of reliability process. A separation index based on Rasch should not lower than 2. The role of the separation index is to indicate the number of respondent's capability strata of and the difficulty of the item strata. In this case, only item no 3 exceeding the minimum value of 2 in person separation (PR). While the rest of the values are lower, however nearer to 2 . In this case, the respondents shown two traits of capabilities- either the managed to perceive the significant level of 
indicators or fail to identify them. On the other hand, the item separation indicates a range values between 3.62 to the highest value 6.06 . From this range, it can be concluded that the difficulty of photograph to be assessed by respondents is between 3 to 6 different strata of difficulty. Thus, this states that the images are validated and reliable to be used in actual study.

\section{Indicator Validity Test}

In referring to the medata analysis, only eight indicators are classified to be dominant in the study. However, these indicators require to be tested in the pilot study as to ensure the indicators are able to be measured by the actual targeted group- expert and non-expert. A multiple analyses of investigating the validity of indicators were conducted. The purpose is to ensure the indicators are able to be distinguished by the respondents without any bias and discrimination.

Table 2. Shows the result of point measured correlation

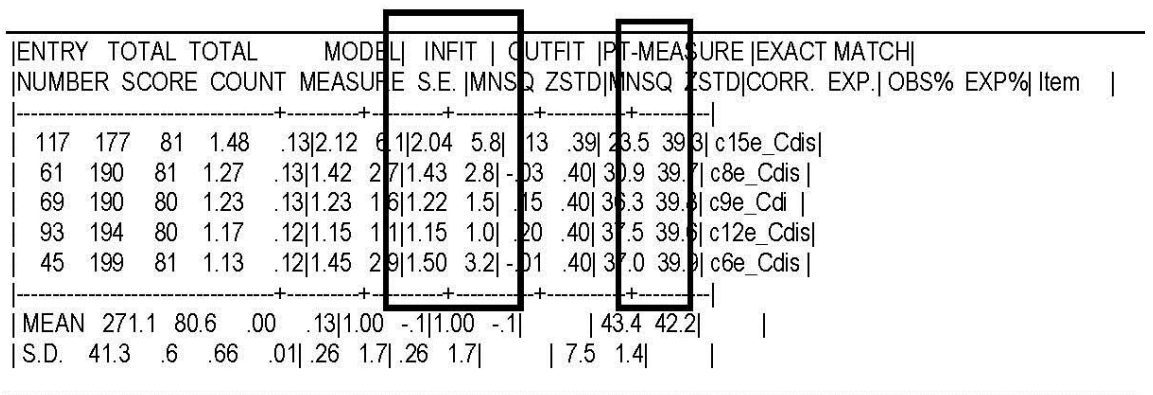

The values of value of point measured correlation (PTMEA CORR) in item polarity test should indicate a positive index before the indicators are accepted and classified to be clearly identified by the respondents. However as, referred to Table 3 , indicator "Disturbance" is consistency detected to have a negative index. For instance, items such as C8e_Cdis and C6e_Cdis both indicate values of -0.3 and -0.1 . To be concluded, the indicator requires to be terminated as it creates a bias and confusion for the respondents. In addition, most of the values of Z standard and Means Square (MNSQ) some of the indicator "Disturbance" are exceeding from the acceptance range values of both. According to Linacre (2005) the value of MNSQ should between 0.5 to 1.5. However, for item C15e_Cdis, the MNSQ value is 2.12 exceeding from the range proposed value. In addition, the value of $Z$ standard for the item C15e_Cdis, C8e_Cdis and C6e_Cdis indicate the range value that exceeding from the proposed range by Linacre (2005), which is -2 to +2 . To conclude, the "Disturbance" is excluded from the field test due of biasness. 


\section{Actual Test}

Respondents consisted of 126 stakeholders are participating in the study. The stakeholder sampling are collected by using stratified random sampling, to ensure the variety of respondent participation. The same set of questionnaire is involved in this with a modification of indicator selection based on the improvement of the pilot study result a repetition of the question regarding the indicators was asked to the participants with referring to the five different photographs.

The questionnaire is divided into 2 parts. The first part is aimed to investigate the correlation of demographic factors in affecting the perception process. On the other hand, the second part is aimed to highlight the significance level of indicators in five different images.

\section{Results and Discussions}

The result of stakeholder's demographic stratification is shown in Table below.

\begin{tabular}{lcc}
\hline Educational Background & Population & $\%$ \\
Secondary & 21 & 16.7 \\
Certificate & 9 & 7.1 \\
Diploma & 17 & 13.5 \\
Degree & 79 & 62.7 \\
Age & & \\
$15-20$ & 25 & 19.9 \\
$21-25$ & 72 & 57.1 \\
$26-30$ & 11 & 8.7 \\
$31-35$ & 5 & 4 \\
$36-40$ & 9 & 7.1 \\
41 and above & 4 & 3.2 \\
Gender & & \\
Male & 66 & 52.4 \\
Female & 60 & 47.6 \\
Ethnicity & & \\
Malay & 97 & 77 \\
Chinese & 11 & 8.7 \\
India & 10 & 7.9 \\
others & 8 & 6.4 \\
Familiarity & & \\
1-5 months & & \\
6-12 months & 31 & 24.6 \\
1-6 years & 16 & 12.7 \\
7 years and above & 71 & 56.3 \\
Origin & 7 & 6.5 \\
Melaka & \\
Outside Melaka & 9 & 7.1 \\
Residence area & 117 & 92.9 \\
Urban & & \\
Urban fringe & 72 & 57.1 \\
Rural & 30 & 23.8 \\
& 24 & 19.1 \\
\hline & & \\
& &
\end{tabular}


Fitry Rosley, M.S., et.al. / Asian Journal of Behavioural Studies, AjBeS, 2(8), Oct / Dec 2017 (p.11-22)

\begin{tabular}{|c|c|c|c|c|c|c|c|c|c|c|}
\hline \multirow{2}{*}{$\begin{array}{l}\text { Factor } \\
\text { Indicator }\end{array}$} & \multicolumn{4}{|c|}{ Educational level } & \multicolumn{2}{|c|}{ Origin } & \multicolumn{4}{|c|}{ Familarity } \\
\hline & Sec & Cent & Dip & Deg. & Native & Non native & $\begin{array}{c}1-5 \\
\text { months }\end{array}$ & $6-12$ months & $1-6$ years & $\begin{array}{c}7 \text { years and } \\
\text { above }\end{array}$ \\
\hline Mystery & -1.54 & 207 & 0.13 & 0.00 & 0.30 & -1.19 & -0.63 & 0.65 & -1.10 & 0.45 \\
\hline Legbilty & 0.00 & -1.50 & 0.80 & -0.42 & -0.49 & 0.19 & 2.62 & 1.20 & -201 & -1.10 \\
\hline Coherence & 2.09 & 0.46 & -0.15 & -1.17 & 2.14 & -0.60 & 2.76 & 0.47 & 1.68 & -1.33 \\
\hline & 0.19 & 0.00 & -1.04 & 0.12 & -2.78 & -0.61 & -0.34 & 1.12 & 0.69 & 0.77 \\
\hline Stewardship & 1.37 & -0.17 & 0.14 & -0.36 & 2.14 & 0.76 & 2.74 & -0.32 & -1.45 & -0.88 \\
\hline Openness & -213 & -0.69 & -0.43 & 1.50 & -2.57 & 0.70 & 1.22 & 0.33 & -0.37 & 0.64 \\
\hline Noturahess & 0.97 & 0.64 & -0.96 & 0.54 & 0.29 & -1.81 & 2.09 & -1.25 & -1.45 & 2.33 \\
\hline Complerity & 0.55 & 1.13 & 1.40 & 0.87 & 0.34 & 0.11 & 1.54 & 0.98 & 1.38 & 0.55 \\
\hline
\end{tabular}

\begin{tabular}{|c|c|c|c|c|c|c|c|c|c|c|c|c|c|}
\hline \multirow{2}{*}{$\begin{array}{l}\text { Factor } \\
\text { Indiczator }\end{array}$} & \multirow{2}{*}{\multicolumn{3}{|c|}{$\begin{array}{c}\text { AgE }_{35-35} \\
26-30\end{array}$}} & \multicolumn{3}{|c|}{ Gender } & \multicolumn{3}{|c|}{ Ethnicity } & \multicolumn{4}{|c|}{ Residency } \\
\hline & & & & $36-40$ & 16 & Fe & Ma & $\mathrm{Ch}$ & Ind & On & Ur & to & Ru \\
\hline Mystery & -154 & 2.07 & 0.13 & 0.00 & 0.23 & 1.16 & 1.59 & 165 & 0.12 & -1.14 & 0.77 & 0.54 & 0.63 \\
\hline Legbility & 0.80 & -0.28 & -1.17 & -0.79 & 0.84 & -1.46 & -1.73 & -1.13 & -1.57 & -0.49 & 0.81 & 2.35 & 1.36 \\
\hline Coherence & $\begin{array}{l}2.09 \\
1.45\end{array}$ & $\begin{array}{r}0.46 \\
-1.08\end{array}$ & $\begin{array}{l}-0.15 \\
0.72\end{array}$ & $\begin{array}{l}-1.17 \\
-0.51\end{array}$ & $\begin{array}{l}1.24 \\
0.20\end{array}$ & $\begin{array}{l}0.76 \\
0.29\end{array}$ & $\begin{array}{l}0.63 \\
1.24\end{array}$ & $\begin{array}{c}0.53 \\
-2.14\end{array}$ & $\begin{array}{l}-2.36 \\
-0.65\end{array}$ & $\begin{array}{l}-0.18 \\
-1.09\end{array}$ & $\begin{array}{c}1.63 \\
-0.41\end{array}$ & $\begin{array}{l}0.02 \\
0.20\end{array}$ & $\begin{array}{l}1.38 \\
1.34\end{array}$ \\
\hline & 0.00 & 0.65 & -1.66 & 0.92 & 0.70 & 0.81 & 0.00 & -1.63 & -0.18 & 2.31 & -0.63 & 0.45 & 0.00 \\
\hline Stewardship & -0.47 & 0.00 & 1.18 & -1.03 & 0.65 & 0.04 & 1.36 & -265 & -0.78 & -0.77 & 1.03 & -0.26 & 0.00 \\
\hline Openness & -213 & -0.69 & -0.43 & 1.50 & -0.20 & -1.71 & -0.72 & 305 & 0.16 & -1.36 & 0.25 & -0.34 & 0.56 \\
\hline Naturahess & 1.22 & -0.64 & -0.16 & 0.00 & -0.17 & 0.00 & -1.21 & 0.19 & 1.15 & 2.31 & -0.71 & 0.03 & 0.67 \\
\hline Comslexity & 0.94 & 1.15 & 1.35 & 1.79 & 0.68 & 0.54 & 1.77 & 0.10 & 0.25 & 1.46 & 1.62 & 0.78 & 0.99 \\
\hline
\end{tabular}

*4 Bold value indicates that the indicator is bias to the group

The overall distribution of the questionnaire managed to represent the categories of the demographic factors which are affecting the result of human perception (Bauer et al. 2009; Paquette \& Domon 2003; Paquette \& Domon 2001; Williams 2011; Groot \& Born 2003; Swanwick 2009; C. M. Hagerhall 2000). Thus, the next stage is to identify the correlation of these factors with the preference of indicators by both groups of stakeholder and expert by using DIF test within the Rasch Model analysis. The function of DIF analysis is used to detect the difficulty level of a group and comparing the result with another group of the same capability (Luppescu, 1993). It is able to detect the discriminate item that causes difficulty and easiness to a certain group to predict as the group compared to other groups. The range of difficulty in T-Test should be between -2 to +2 . The positive values indicate that the respondents are able to assess the item and vice versa.

Correlation Analysis

The tables below indicate the correlation results between seven identified demographic factors and the selected seven indicators, performed by the T-test in DIF analysis. The predictor indicators for assessing the visual aesthetic assessment in the rural area are presented in both of the tables. All tables indicate the correlation result between seven indicators and seven demographic factors- 22 sub attributes of the stakeholders. 
The results of DIF analysis can be divided into three different parts indicators that are extremely hard to be assessed; indicators that are extremely easy to be assessed and indicators that able to represent the different group capabilities. The correlation value of indicators such as between Legibility and urban fridge (t-value: 2.35), between Mystery and range age 26-30, (t-value: 2.07), between Coherence and range age 21-25, (t-value: 2.09),between Coherence and native (t- value 2.14), between Naturalness and other ethnicity (t- value 2.31),between Mystery and certification level (t-value:2.07), between Legibility and certification level (tvalue: 2.07), between Legibility and range period 1-5 months (T-value 2.62), between Coherence and range period 1-5 months (T-value 2.76), between Stewardship and range period 1-5 months (t- value 2.14), between Stewardship and range period 1-5 months (T-value 2.74), between Naturalness and range period 1-5 months (T-value 2.09) and lastly between Naturalness and range period 7 years and above ( $T$ value 2.33) are occurred relatively easy and not able to measure the capabilities of respondents. This resulted from the t-value whereby these values are exceeded value of 2.For instance, the correlation value of indicators: - between Coherence and Indian ethnicity ( $t$ - value -2.36 ), between Coherence and Chinese ethnicity ( $t-$ value -2.14 ), between Coherence and Chinese ethnicity (t- value -2. 64), between Legibility and range period of 1 to 6 years (t-value -2.10 ), between Coherence and native (t-value -2.78 ) and between Openness and secondary level (t-value-2.13). The results of t-value for these indicators are lower than -2 and predicted to be the hardest indicators and unable to measure the capabilities of the groups. From the result, the stakeholders believed that Complexity is the most significant indicator to assess the different criteria of the landscape attributes. None of the correlation indicates any T-values that higher or lower than 2. Complexity has become the only indicator that shows a same authenticity to groups and suggested being retained for the stakeholder evaluation.

In reference to the result, the study managed to fulfill the requirement of identify the homogenous indicator to represent the stakeholder's perception. The validation process based on stratification analyses of Different Item Functioning (DIF), successfully to reveal the significant level of indicator regardless the differences of demographic factors such as age, education level and so forth. This is parallel to the the Biophilic Theory proposed by Peter H. Kahn Jr in his study on investigate people attachment to their surroundings. He mentioned that human are genetically fond and depend on surrounding to fulfill their needs and necessity (Kahn 1997). These attributes affecting the human perception and cognition process of human behavior in environment.

Based on the DIF analysis, Complexity has shown a promising pattern of acceptance by stakeholders. It is the most significant indicator that able to be assessed by stakeholders in the different images. It can be inferred that, Complexity is the only indicator to represent the similarity of stakeholder's perception in the rural landscape. 


\section{Conclusion}

This study focused on identification of homogenous indicators, derived from the theory driven indicators. As many of the indicators were developed from cognition and perception related theories, nonetheless it required a validation process. Therefore, a statistical approach by using DIF analysis based on Rasch Model analysis is implemented in the study. Aspect such as demographic factors is being considered in order to determine the indicator that able to represent people perception. The analysis result enables the study to identify the homogenous indicator, which is preferable by the stakeholders. Despite the finding successfully to project Complexity as the homogenous indicator, it still requires a further study. Limitation factors such as restricted study on rural landscape perception, however, contribute to a gap for a future research. As for future study, the validation process of the theory driven indicators can be expanded in term of different target groups such as experts and application in other landscape themes. The similar process of validation could be adopted and implemented for similar future research.

\section{Acknowledgement}

The authors gratefully acknowledge the financial support provided by the Ministry of Higher Education Malaysia and research grant (vote: Q.J130000.2521.07H94) of Universiti Teknologi Malaysia (UTM), the cooperation and research support from the Department of Landscape Architecture, Faculty of Built Environment, Universiti Teknologi Malaysia.

\section{References}

Arriaza, M. et al., 2004. Assessing the visual quality of rural landscapes. Landscape and Urban Planning, 69(1), pp.115-125.

Bauer, N., Wallner, A. \& Hunziker, M., 2009. The change of European landscapes: human-nature relationships, public attitudes towards rewilding, and the implications for landscape management in Switzerland. Journal of environmental management, 90(9), pp.2910-20.

Bratli, H. et al., 2006. Patterns of variation in vascular plant species richness and composition in SE Norwegian agricultural landscapes. Agriculture, Ecosystems \& Environment, 114(2-4), pp.270-286. A

C. M. Hagerhall, 2000. Clustering Predictors o Landscape Preference in the Traditional Swedish Cultural Landscape: Prospect-Refuge, Mystery, Age and Management. Journal Of Environmental Psychology, (20), Pp.83-90.

Fry, G. et al., 2009. The ecology of visual landscapes: Exploring the conceptual common ground of visual and ecological landscape indicators. Ecological Indicators, 9(5), pp.933-947.

Groot, W.T. De \& Born, R.J.G. Van Den, 2003. Visions of nature and landscape type preferences : an exploration in The Netherlands. Landscape and Urban Planning, 63, pp.127-138. 
Kahn, P., 1997. Developmental Psychology and the Biophilia Hypothesis: Children's Affiliation with Nature, ,. Developmental Review, 17(1), pp.1-61. Lothian, A., 1999. Landscape and the philosophy of aesthetics: is landscape quality inherent in the landscape or in the eye of the beholder? Landscape and Urban Planning, 44(4), pp.177-198.

Negev, M., 2012. Knowledge, data and interests: Challenges in participation of diverse stakeholders in HIA. Environmental Impact Assessment Review, 33(1), pp.48-54.

Ode, A. et al., 2009. Indicators of perceived naturalness as drivers of landscape preference. Journal of environmental management, 90(1), pp.375-83.

Ode, Å., Tveit, M.S. \& Fry, G., 2010. Advantages of using different data sources in assessment of landscape change and its effect on visual scale. Ecological Indicators, 10(1), pp.24-31.

Ode, Å.K. \& Fry, G.L.A., 2002. Visual aspects in urban woodland management. Urban Forestry \& Urban Greening, 46(1).

Palmer, J.F. \& Hoffman, R.E., 2001. Rating reliability and representation validity in scenic landscape assessments. Landscape and Urban Planning, 54(1-4), pp.149-161.

Paquette, S. \& Domon, G., 2003. Changing ruralities, changing landscapes: exploring social recomposition using a multi-scale approach. Journal of Rural Studies, 19(4), pp.425-444.

Paquette, S. \& Domon, G., 2001. Trends in rural landscape development and sociodemographic recomposition in southern Quebec (Canada). Landscape and Urban Planning, 55(4), pp.215-238.

Rosley, M.S.F., Lamit, H. \& Abdul, S.R., 2013. Perceiving the Aesthetic Value of the Rural Landscape through Valid Indicators. Procedia - Social and Behavioral Sciences, 85, pp.318-331.

Sapawi, R. \& Said, I., 2012. Constructing Indices Representing Physical Attributes for Walking in Urban Neighborhood Area. Procedia - Social and Behavioral Sciences, 50(July), pp.179-191.

Sayadi, S., Gonzalezroa, M. \& Calatravarequena, J., 2009. Public preferences for landscape features: The case of agricultural landscape in mountainous Mediterranean areas. Land Use Policy, 26(2), pp.334-344.

Stamps, a, 2004. Mystery, complexity, legibility and coherence: A meta-analysis. Journal of Environmental Psychology, 24(1), pp.1-16.

Swanwick, C., 2009. Society 's attitudes to and preferences for land and landscape. Land Use Policy, 26, pp.6275.

Tveit, M., Ode, Å. \& Fry, G., 2006a. Key concepts in a framework for analysing visual landscape character. Landscape Research, 31(3).

Tveit, M., Ode, A. \& Fry, G., 2006b. Key concepts in a framework for analysing visual landscape character. Landscape Research, 31(3), pp.229-255.

Williams, K., 2011. Relative acceptance of traditional and non-traditional rural land uses: Views of residents in two regions, southern Australia. Landscape and Urban Planning, 103(1), pp.55-63. 
Fitry Rosley, M.S., et.al. / Asian Journal of Behavioural Studies, AjBeS, 2(8), Oct / Dec 2017 (p.11-22)

Zube', E.H., Sell', J.L. \& Taylor, J.G., 1982. Landscape Perception: Research, Application and Theory. Landscape Planning, 9(9), pp.1-33. 